\title{
Metal oxide heteroepitaxy: Stranski-Krastanov growth for iron oxides on $\operatorname{Pt}(111)$
}

\author{
W. Weiss and M. Ritter \\ Fritz-Haber-Institut der Max-Planck-Gesellschaft, Faradayweg 4-6, 14195 Berlin, Germany \\ (Received 18 June 1998; revised manuscript received 8 September 1998)
}

\begin{abstract}
The epitaxial growth of iron oxide films on $\mathrm{Pt}(111)$ substrates was investigated by scanning tunneling microscopy and low-energy electron diffraction. The film growth was accomplished by repeated cycles of iron deposition and subsequent oxidation at $p\left(\mathrm{O}_{2}\right)=10^{-6}$ mbar. For oxidation temperatures of $870 \mathrm{~K}$ second and third $\mathrm{FeO}(111)$ layers grow layer by layer, whereas for oxidation temperatures of $1000 \mathrm{~K}$ only one $\mathrm{FeO}(111)$ monolayer is formed. On top of the $\mathrm{FeO}(111)$ films a homogeneous nucleation of $\mathrm{Fe}_{3} \mathrm{O}_{4}(111)$ islands takes place, resulting in a Stranski-Krastanov growth for iron oxides on $\mathrm{Pt}(111)$. The islands grow in the $\mathrm{Fe}_{3} \mathrm{O}_{4}$ bulk structure laterally much faster than vertically, forming flat platelets with heights up to $100 \AA$ and hexagonal and triangular basal planes $1000-5000 \AA$ in diameter. The islands only expose low index $\{\overline{1} 11\}$ and $\{2 \overline{1} \overline{1}\}$ facet planes, and their growth can be described by an Ostwald ripening mechanism that takes place during each oxidation cycle. Eventually the islands coalesce and form smooth $\mathrm{Fe}_{3} \mathrm{O}_{4}(111)$ films at least $150 \AA$ thick. The atomic and mesoscopic surface roughness of these films depends on the growth temperature, where the latter ranges between 40 and $100 \AA$ on a length scale of $1 \mu \mathrm{m}$. By a high-pressure oxidation at $p\left(\mathrm{O}_{2}\right)$ $=10^{-1}$ mbar the $\mathrm{Fe}_{3} \mathrm{O}_{4}(111)$ films were transformed into well-ordered $\alpha-\mathrm{Fe}_{2} \mathrm{O}_{3}(0001)$ films with similar surface morphologies. In all oxide phases formed the hexagonal oxygen (111) planes are aligned to the $\mathrm{Pt}(111)$ substrate surface lattice. The film growth is discussed in terms of surface and interfacial energies, oxidation and growth kinetics, as well as thermodynamic stability ranges of the different oxide phases.
\end{abstract}

[S0163-1829(99)11007-5]

\section{INTRODUCTION}

The importance of metal oxides in various fields of technology has led to an increasing number of surface science studies on these materials during the last decade. ${ }^{1-3}$ It turned out that the preparation of ordered metal oxide surfaces with defined structures and chemical compositions plays a key role in this field of research. It also is desirable to control the concentration of atomic surface defects, which have distinct properties that can dominate the surface chemistry of metal oxides. ${ }^{4}$ In this context the growth of thin epitaxial oxide films onto conducting metal substrates is becoming an important technique. Well-ordered thin films were obtained by oxidizing the surface region of metal single crystals. ${ }^{5}$ Heteroepitaxial metal oxide growth was accomplished by molecular-beam epitaxy in oxygen atmosphere, ${ }^{6,7}$ and in other reactants like $\mathrm{NO}_{2},{ }^{8}$ as well as by oxygen-plasmaassisted molecular-beam epitaxy. ${ }^{9-11}$ Another technique is metal deposition and subsequent oxidation. ${ }^{12-14}$

Whereas a detailed picture of the microscopic processes during epitaxial growth of metals has developed in the past, ${ }^{15}$ not much is known about metal oxides in this respect. As metal oxides are binary compounds, the oxide stoichiometry is thermodynamically determined by a certain oxygen gas phase pressure. ${ }^{16}$ However, since epitaxial growth always takes place under nonequilibrium conditions, the oxidation kinetics also plays an important role for the oxide phase formation. This was found for iron oxides grown by oxygenplasma-assisted molecular-beam epitaxy, ${ }^{9}$ where parameters like oxygen gas pressure, metal-deposition rate, and substrate temperature turned out to be critical for the oxide phases and crystallographic qualities of the films obtained. In the case of oxide on oxide growth, previous studies revealed that the lattice mismatch between the oxygen sublattices mainly determines the interfacial energies and therefore the epitaxial growth mode.

In this work we grow single-crystalline iron oxide films on $\mathrm{Pt}(111)$ substrates by repeated cycles of iron deposition at room temperature and subsequent oxidation at elevated temperatures. Iron oxide is an important material in heterogeneous catalysis, ${ }^{17}$ in particular for the dehydrogenation of ethylbenzene to styrene. ${ }^{18,4}$ Several iron oxide phases with different crystal structures exist, ${ }^{19}$ and their thermodynamic stability ranges are given by the iron-oxygen phase diagram. ${ }^{20} \mathrm{FeO}$ (wüstite) crystallizes in the cubic sodium chloride structure, where the $\mathrm{O}^{2-}$ anions form a cubic close packed fcc sublattice with $\mathrm{Fe}^{2+}$ cations located in the octahedral interstitials. $\mathrm{Fe}_{3} \mathrm{O}_{4}$ (magnetite) crystallizes in the cubic inverse spinel structure, where the $\mathrm{O}^{2-}$ anions also form a cubic close packed fcc sublattice with the tetrahedral interstitials occupied by $\mathrm{Fe}^{3+}$ cations and octahedral interstitials occupied by equal numbers of $\mathrm{Fe}^{2+}$ and $\mathrm{Fe}^{3+}$ cations. $\alpha-\mathrm{Fe}_{2} \mathrm{O}_{3}$ (hematite) crystallizes in the hexagonal corundum structure, where the $\mathrm{O}^{2-}$ anions form a hexagonal close packed hcp sublattice with $\mathrm{Fe}^{3+}$ cations located in octahedral interstitials.

Ordered iron oxide films were grown by iron depositionoxidation cycles onto a $\operatorname{Pt}(111)$ substrate by Vurens et al. for the first time. ${ }^{21,22}$ As known from atomic resolution scanning tunneling microscopy (STM) images in conjunction with theoretical image simulations ${ }^{23,24}$ and from photoelectron diffraction experiments, ${ }^{25}$ the first monolayer consists of a hexagonal iron-oxygen bilayer forming an $\mathrm{FeO}(111)$ structure with oxygen on top as shown in Fig. 1(a). It is slightly expanded laterally when compared to the $\mathrm{FeO}$ bulk structure, resulting in a $12 \%$ lattice mismatch to the platinum substrate. 

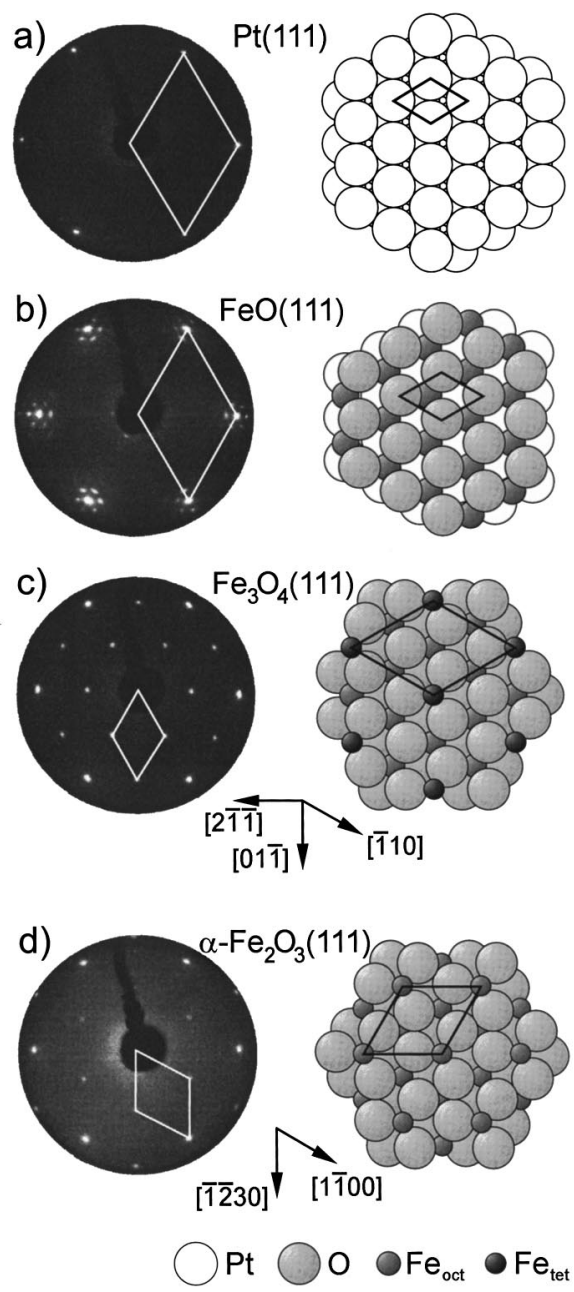

FIG. 1. LEED patterns at $E=60 \mathrm{eV}$ (left) and top views of the corresponding unreconstructed surface structures (right) of the $\operatorname{Pt}(111)$ substrate (a), and the different iron oxide films grown on $\operatorname{Pt}(111)$ (b)-(d). The unit cells in real and reciprocal space and the crystallographic directions in the cubic (a)-(c) and hexagonal crystal structures are indicated (d). The epitaxial relationships between the oxide films and the substrate surface are reflected in this figure.

We note that this film does not represent an $\mathrm{FeO}$ bulk oxide, which requires at least three $\mathrm{Fe}-\mathrm{O}$ bilayer repeat units, but nevertheless we will call it an $\mathrm{FeO}$ monolayer. Later thicker iron oxide films with $\mathrm{Fe}_{3} \mathrm{O}_{4}$ and $\mathrm{Fe}_{2} \mathrm{O}_{3}$ stoichiometries were prepared the same way. ${ }^{26,14}$ The $\mathrm{Fe}_{3} \mathrm{O}_{4}(111)$ surface structure was determined by a low-energy electron diffraction (LEED) intensity analysis, ${ }^{27,28}$ and the electronic structures of these films have been studied by photoelectron spectroscopy ${ }^{29}$ and $\mathrm{x}$-ray absorption spectroscopy. ${ }^{30}$

Here we present a detailed scanning tunneling microscopy study of the epitaxial iron oxide film growth from submonolayer up to multilayer coverage, where we focus on the film morphologies at lateral length scales between 100 and 10000 $\AA(1 \mu \mathrm{m})$. Atomic resolution STM images of the film surfaces will be presented elsewhere. The role of the oxidation temperature and the amount of iron deposited in each deposition-oxidation cycle for the film growth is studied systematically. This gives new insight into the growth mechanism of the iron oxide and of metal oxides in general. It is demonstrated that the morphology and surface defect struc- ture of thicker $\mathrm{Fe}_{3} \mathrm{O}_{4}$ and $\alpha-\mathrm{Fe}_{2} \mathrm{O}_{3}$ films grown with this technique can be varied by choosing different growth conditions, which allows us to design metal oxide model systems with defined stoichiometries and surface structures, including nonideal defect structures.

\section{EXPERIMENT}

The experiments were carried out in an UHV system described in detail in Ref. 31. It consists of an analysis chamber equipped with a commercial STM head (Burleigh Instruments), a rearview LEED optics (Omicron), and a cylindrical mirror analyzer Auger spectrometer (Omicron). The base pressure of the system is $5 \times 10^{-11}$ mbar. Several gas inlet valves, an ion bombardment gun, and an electron beam evaporator were used for the sample preparation, and oxidation treatments up to $10^{-6}$ mbar oxygen partial pressure were performed in this chamber. Attached to the analysis chamber is a preparation chamber which can be completely separated by a gate valve after the sample transfer. It is used for highpressure oxidation treatments performed with a radiation heater as described in Ref. 31. All STM measurements were performed at room temperature in the constant current mode. Tungsten tips were etched electrochemically in 3-molar $\mathrm{NaOH}$ solution and placed afterwards into the STM tip magazine. Before performing the measurements, the tips were cleaned in situ by electron bombardment.

The platinum crystal is mounted onto a sample holder fabricated of single-crystalline sapphire. It is heated by electron bombardment from the back and the temperature is measured with a chromel-alumel thermocouple spotwelded to the side of the crystal. The $\mathrm{Pt}(111)$ substrate surface was cleaned by numerous cycles of argon sputtering $(1 \mathrm{keV}, 3 \mu \mathrm{A})$ and subsequent annealing to $1200 \mathrm{~K}$ in $10^{-7}$ mbar oxygen. A final flash to $1300 \mathrm{~K}$ without oxygen resulted in a clean and well-ordered surface exhibiting a sharp $(1 \times 1)$ LEED pattern and no contamination signals in Auger electron spectroscopy. $\mathrm{FeO}$ and $\mathrm{Fe}_{3} \mathrm{O}_{4}$ films were grown onto the platinum substrate by repeatedly depositing certain amounts of iron at room temperature and subsequently oxidizing the iron at temperatures between 870 and $1000 \mathrm{~K}$ in $10^{-6}$ mbar oxygen partial pressure. $\alpha-\mathrm{Fe}_{2} \mathrm{O}_{3}$ films were obtained by oxidizing $\mathrm{Fe}_{3} \mathrm{O}_{4}$ multilayer films for $5 \mathrm{~min}$ at $T=1000 \mathrm{~K}$ in $10^{-1} \mathrm{mbar}$ oxygen partial pressure. After the high-pressure oxidation the $\alpha-\mathrm{Fe}_{2} \mathrm{O}_{3}$ films were cooled down in the oxygen atmosphere, then the oxygen was pumped off and the films were transferred back into the analysis chamber. All iron oxide films were clean as monitored by Auger electron spectroscopy.

\section{RESULTS}

\section{A. Determination of the iron oxide phases by LEED}

On the left side in Fig. 1 the LEED patterns of the clean $\mathrm{Pt}(111)$ substrate surface (a) and of the three different iron oxide films grown on the $\mathrm{Pt}(111)$ surface (b)-(d) are shown. On the right side top views of the corresponding unreconstructed, bulk-terminated surface structures are displayed. The corresponding real-space and reciprocal-space unit cells are indicated. The hexagonal unit cell of the $\mathrm{Pt}(111)$ surface has a lattice constant of $2.77 \AA$. The first $\mathrm{FeO}(111)$ layer has 

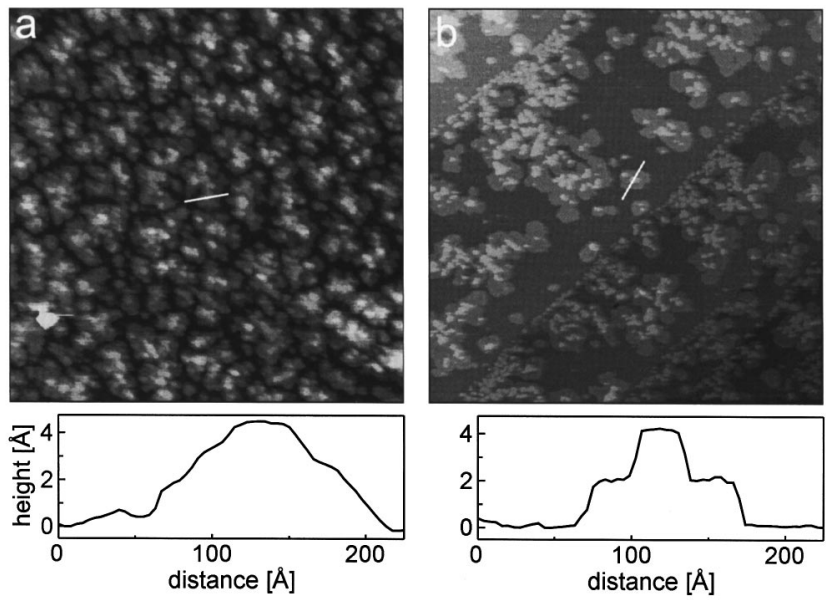

FIG. 2. $2000 \times 2000-\AA^{2}$ STM images of the Pt(111) surface after deposition of $1 \mathrm{ML}$ iron at room temperature (a) and $0.7 \mathrm{ML}$ iron at $T=500 \mathrm{~K}(\mathrm{~b})$. Below cross sections along the white lines are shown.

a hexagonal unit cell with a lattice constant of $3.1 \AA$, which corresponds to the interatomic distance within the oxygen (111) plane and which is $12 \%$ larger than the substrate lattice spacing. This lattice mismatch creates an $\mathrm{FeO}$ coincidence structure, which exhibits the characteristic satellite LEED pattern shown in Fig. 1(b) and a large moiré superstructure visible in atomic resolution STM images as discussed in detail in Ref. 32.

Figure 1(c) displays the LEED pattern of an $\mathrm{Fe}_{3} \mathrm{O}_{4}(111)$ film which is at least $150 \AA$ thick, where the satellite spots of the $\mathrm{FeO}(111)$ monolayer film have disappeared. As depicted on the right side, it corresponds to an unreconstructed $\mathrm{Fe}_{3} \mathrm{O}_{4}(111)$ surface structure which has a hexagonal unit cell with a lattice constant of $5.94 \AA$ and an interatomic distance of $2.97 \AA$ within the oxygen (111) planes. This surface exposes $\frac{1}{4}$ monolayer of tetrahedrally coordinated iron atoms in the topmost layer, as determined by a dynamical LEED intensity analysis. ${ }^{27}$ Figure $1(\mathrm{~d})$ shows the LEED pattern of an $\alpha$ - $\mathrm{Fe}_{2} \mathrm{O}_{3}(0001)$ film at least $150 \AA$ thick, which was obtained by oxidizing an $\mathrm{Fe}_{3} \mathrm{O}_{4}(111)$ film in $10^{-1}$ mbar oxygen. The pattern corresponds to an unreconstructed $\alpha-\mathrm{Fe}_{2} \mathrm{O}_{3}(0001)-(1 \times 1)$ surface structure, which has a hexagonal unit cell with a lattice constant of $5 \AA$ that is rotated by $30^{\circ}$ against the unit cell on $\mathrm{Fe}_{3} \mathrm{O}_{4}(111)$. Photoelectron spectroscopy measurements revealed that these hematite films contain only $\mathrm{Fe}^{3+}$ and no $\mathrm{Fe}^{2+}$ species. ${ }^{30}$

The LEED patterns reflect the epitaxial relationships between the oxide films and the substrate lattice, which will be discussed in Sec. IV. They allow us to identify the iron oxide phase of the epitaxially grown films. This was also possible by inspection of atomic resolution STM images obtained on the films (not shown here), where we observed surface structures displaying surface unit cells of the different oxide phases.

\section{B. Fe morphology before oxidation}

Figure 2(a) shows a $2000 \times 2000-\AA^{2}$ STM image of a large terrace on the $\mathrm{Pt}(111)$ surface after about one monolayer (ML) of iron was deposited at room temperature. As can be seen in the cross section below, the iron forms clus-
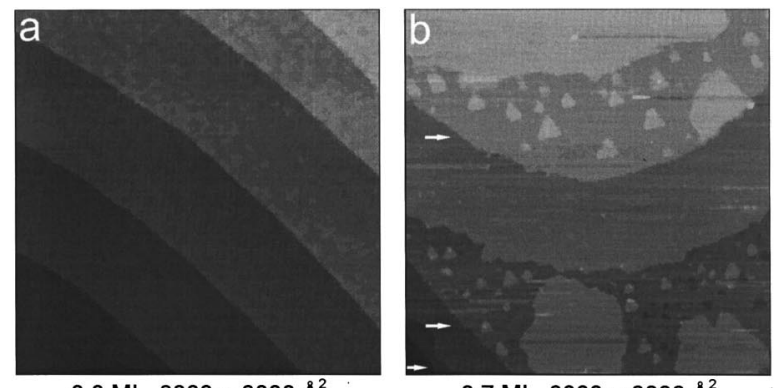

$0.0 \mathrm{ML}, 6000 \times 6000 \AA^{2}$

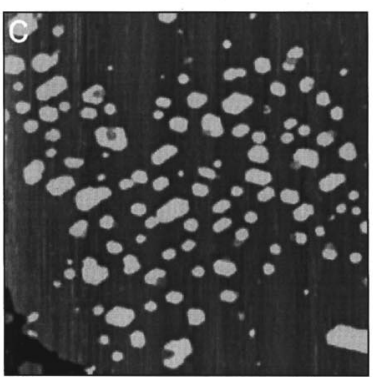

$1.2 \mathrm{ML}, 4000 \times 4000 \AA^{2}$

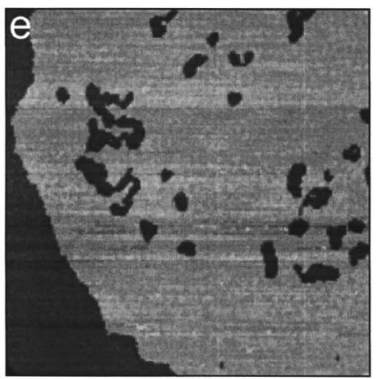

$1.9 \mathrm{ML}, 6000 \times 6000 \AA^{2}$

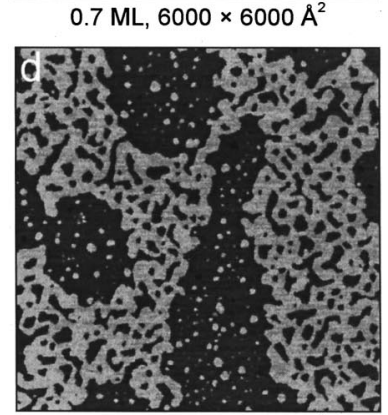

$1.5 \mathrm{ML}, 4000 \times 4000 \AA^{2}$

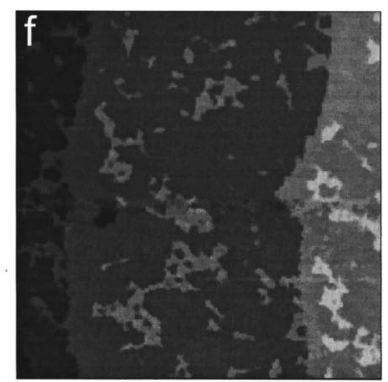

$2.2 \mathrm{ML}, 6000 \times 6000 \AA^{2}$

FIG. 3. STM images of the initial iron oxide growth stages for an oxidation temperature of $870 \mathrm{~K}$. At this temperature $\mathrm{FeO}(111)$ films grow layer by layer up to $2.5 \mathrm{ML}$ thickness. The substrate step structure underneath the oxide overlayers does not change considerably.

ters with lateral dimensions of about $100 \AA$ and heights between 2 and $5 \AA$. No flat iron terraces are visible. The background intensity in the Pt(111) LEED pattern has increased and no additional LEED spots are observed. This indicates that no good crystalline order is established in the iron clusters when deposited at room temperature.

Figure 2(b) shows another $2000 \times 2000-\AA^{2}$ surface area after deposition of about half a ML of iron at an elevated substrate temperature of $500 \mathrm{~K}$. Here five platinum substrate terraces separated by monoatomic steps with the nominal platinum step height of $2.26 \AA$ are visible. In general, terraces more than $1000 \AA$ wide are separated by monoatomic steps, as shown in Fig. 3(a). On the scale of several $\mu \mathrm{m}$, such flat regions are separated by steep step bunching regions, where many steps separating terraces only 10 to $100 \AA$ wide create height differences up to several $1000 \AA$. The step structure of the clean platinum substrate has not changed upon iron deposition at $T=500 \mathrm{~K}$, as can be seen in Fig. 2(b). First layer iron islands 50 to $200 \AA$ in diameter have formed, and some of them have coalesced at this stage. Fewer islands form on upper terraces than on lower terraces in the vicinity of substrate step edges, indicating a favored downward step diffusion for $\mathrm{Fe}$ on $\mathrm{Pt}(111)$. On top of these first layer $\mathrm{Fe}$ regions, smaller second layer $\mathrm{Fe}$ regions have 
formed, resulting in a three-dimensional growth mode for $\mathrm{Fe}$ on $\mathrm{Pt}(111)$. It can be seen in the cross section of Fig. 2(b) that first and second iron layer regions are atomically flat and clearly separated by monoatomic steps about $2 \AA$ high. This indicates a good crystalline order of the iron layers, which is also reflected by the lower LEED background intensity when compared to the LEED pattern observed after roomtemperature deposition. No LEED spots besides the substrate spots appear upon iron deposition at this elevated temperature either.

The measured step height of $2 \AA$ agrees with the distance between consecutive (111) or (110) layers in $\gamma$-Fe or $\alpha$-Fe, respectively. Strained fcc $\gamma$-Fe was stabilized up to $11 \mathrm{ML}$ thickness on $\mathrm{Cu}(100),{ }^{33}$ and pseudomorphic growth of $\gamma$-Fe(111) was also observed on $\mathrm{Cu}(111) .{ }^{34}$ Since no new LEED spots are visible, we assume a pseudomorphic growth of $\gamma$ - $\mathrm{Fe}(111)$ on $\mathrm{Pt}(111)$, despite the large lattice mismatch of $8 \%$ for these materials.

\section{Initial iron oxide growth at $T=870 \mathrm{~K}$}

Figure 3 shows subsequent stages of the initial iron oxide growth for an oxidation temperature of $870 \mathrm{~K}$. The images display $6000 \times 6000$ - and $4000 \times 4000-\AA^{2}$ area scans. In (a) the clean $\operatorname{Pt}(111)$ substrate surface with terraces separated by monoatomic steps is shown. In (b)-(f) the oxide overlayer coverage increases from 0.7 to $2.2 \mathrm{ML}$. For all these coverages characteristic satellite LEED patterns similar to the one displayed in Fig. 1(b) are observed. However, upon closer inspection of the LEED patterns slight differences show with increasing $\mathrm{FeO}$ coverage, which are due to structural transitions that lead to four slightly different $\mathrm{FeO}(111)$ coincidence structures on $\mathrm{Pt}(111) .{ }^{32}$ High-resolution STM images allow us to identify these different structures that form at the corresponding coverages on the first and second $\mathrm{FeO}(111)$ layer surfaces.

In Fig. 3(b) about $70 \%$ of the platinum surface is covered by the first FeO layer, which can be identified by its characteristic moiré pattern. The terraces of the platinum substrate separated by monoatomic steps are marked by arrows. Starting at these steps, a closed overlayer always forms on the lower terrace, whereas overlayer islands and bare substrate regions coexist on larger upper terraces near the step edges. Smaller platinum terraces, like those in the lower left corner in Fig. 3(b), are partly covered by a closed overlayer and no overlayer islands form on the remaining bare parts of such small terraces. This shows that a downward step diffusion for iron or iron oxide on $\operatorname{Pt}(111)$ is preferred during the iron oxide formation. No second layer islands have formed on top of the first layer at this growth stage, yet. The platinum substrate steps have almost not changed their morphology when compared to the uncovered surface. Also upon further $\mathrm{FeO}$ growth only small morphological changes of the platinum substrate are observed. These changes occur as a slight increase in the $\operatorname{Pt}(111)$ step kink density, as visible in Figs. 3(c), 3(e), and 3(f).

Upon completion of the first $\mathrm{FeO}$ layer the first change in the atomic $\mathrm{FeO}(111)$ coincidence structure takes place, ${ }^{32}$ and second $\mathrm{FeO}$ layer islands start to grow. In Fig. 3(c) these islands are 50 to $400 \AA$ in diameter. Their step edges run along the $[\overline{1} 10]$ and $[01 \overline{1}]$ directions of the $\mathrm{FeO}(111)$ over- layer. As the growth proceeds, the morphology of the second layer changes in a characteristic manner, which can be seen on the 1.5-ML-thick film shown in Fig. 3(d). In those regions where the coverage is sufficient for the coalescence of second layer islands, the surface morphology is characterized by the existence of vacancy islands that expose the first $\mathrm{FeO}(111)$ layer underneath. The remaining surface parts are characterized by isolated small second layer islands. The step edges of both islands and vacancy islands run along the [ $\overline{1} 10]$ and [01 $\overline{1}]$ directions on $\mathrm{FeO}(111)$. At about $1.7 \mathrm{ML}$ coverage all second layer islands have coalesced and the whole surface is characterized by vacancy islands. Together with the formation of these vacancy islands in the second $\mathrm{FeO}$ layer the second change in the atomic $\mathrm{FeO}(111)$ coincidence structure takes place. ${ }^{32}$ In Fig. 3(e) the second layer is almost completed. Third layer island growth only starts after completion of the second $\mathrm{FeO}(111)$ layer. At this point the third change in the $\mathrm{FeO}(111)$ coincidence structure takes place. ${ }^{32}$ In Fig. 3(f) the coverage is $2.2 \mathrm{ML}$ and third FeO layer islands up to $500 \AA$ in diameter have formed. Note the difference in shape between the second and third layer islands at their initial growth stages, as visible in Figs. 3(c) and 3(f), respectively. The largest FeO coverage we could observe upon further growth was $2.5 \mathrm{ML}$. Upon completion of the second $\mathrm{FeO}$ layer, $\mathrm{Fe}_{3} \mathrm{O}_{4}(111)$ islands start to grow as will be discussed in Sec. III F.

To summarize, at $870 \mathrm{~K}$ oxidation temperature iron oxide grows layer by layer onto $\mathrm{Pt}(111)$ up to $2.5 \mathrm{ML}$ thickness. Each layer consists of an $\mathrm{FeO}(111)$ bilayer that is laterally expanded. No considerable change of the platinum substrate morphology and step structure underneath the oxide film is observed under these conditions.

\section{Initial iron oxide growth at $T=1000 \mathrm{~K}$}

A different growth behavior is observed if the iron is oxidized at higher temperatures. Figure 4(a) shows a $1 \times 1 \mu \mathrm{m}^{2}$ image of the clean $\mathrm{Pt}(111)$ surface, where terraces about $1500 \AA$ wide are separated by monoatomic steps. In (b) about 0.4 ML $\mathrm{FeO}(111)$ were grown on this surface by oxidizing the iron at $T=1000 \mathrm{~K}$. The characteristic $\mathrm{FeO}(111) / \mathrm{Pt}(111)$ satellite LEED pattern is observed. In contrast to $870 \mathrm{~K}$ oxidation temperature, where the platinum substrate widely keeps its morphology, now the substrate step structure has changed considerably and no straight step edges exist anymore. Starting at platinum steps like, for example, the step marked by number 1, again the lower terrace is covered by a closed oxide overlayer and the upper terrace by a few small overlayer islands. However, at locations like those marked by number 2 , the oxide overlayer on the lower terrace has grown across a former platinum upward step into the upper platinum terrace. Here the oxide replaces platinum atoms formerly located in these regions. Also, overlayer islands like those marked by number 3 have formed. They look "burned" into the platinum terraces, because they grew onto platinum atoms located one platinum layer deeper than the platinum terrace atoms around these islands. Here also platinum substrate atoms were displaced from their former terrace positions during the iron oxidation.

Figure 4(c) shows this oxide growth mechanism at a continued growth stage with an overlayer coverage of $0.7 \mathrm{ML}$. A 


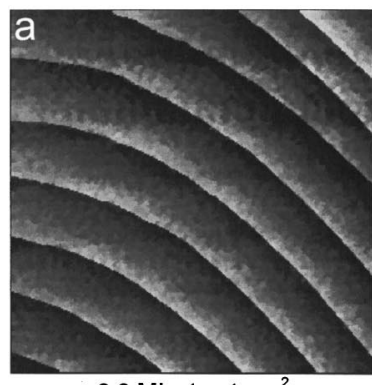

$0.0 \mathrm{ML}, 1 \times 1 \mu \mathrm{m}^{2}$

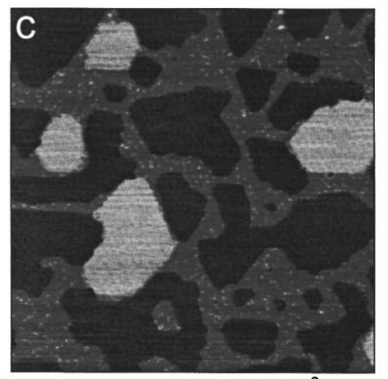

$0.7 \mathrm{ML}, 1100 \times 1100 \AA^{2}$

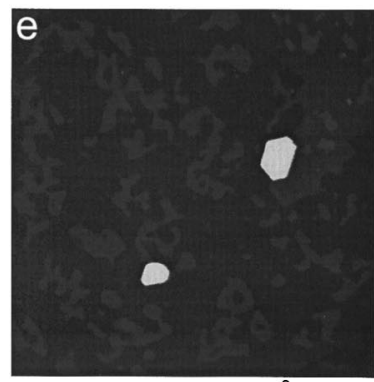

$1.0 \mathrm{ML}, 1 \times 1 \mu \mathrm{m}^{2}$

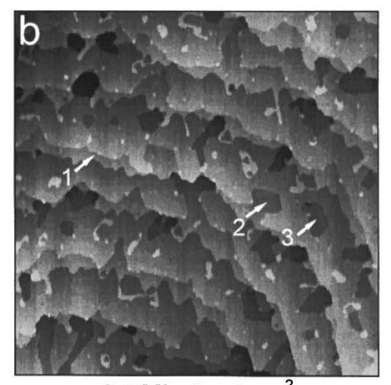

$0.4 \mathrm{ML}, 1 \times 1 \mu \mathrm{m}^{2}$

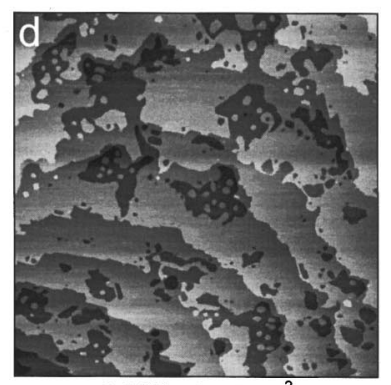

$1.0 \mathrm{ML}, 1 \times 1 \mu \mathrm{m}^{2}$

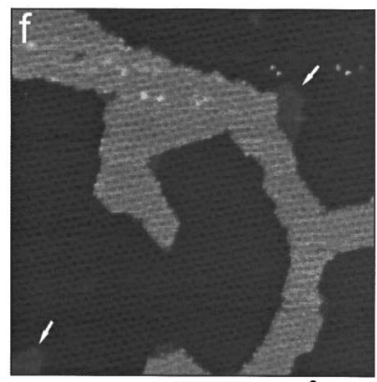

$1.0 \mathrm{ML}, 1100 \times 1100 \AA^{2}$
FIG. 4. STM images of the initial iron oxide growth stages for an oxidation temperature of $1000 \mathrm{~K}$. At this temperature only one $\mathrm{FeO}(111)$ layer forms before $\mathrm{Fe}_{3} \mathrm{O}_{4}(111)$ islands start to grow (e). A roughening of the substrate surface takes place, which can be seen by comparing the images in (a) and (d).

smaller region of $1100 \times 1100 \AA^{2}$ located on one platinum terrace is displayed, where areas on three different heights can be seen. The very bright and very dark surface areas are $\mathrm{FeO}$ covered as can be identified by the moire patterns. These two regions are vertically separated by a monoatomic platinum step. The uncovered platinum surface areas appear on an intermediate height and are characterized by the appearance of numerous small bright dots, which are accounted for adsorbates from the residual gas. The highest-lying overlayer islands have increased in size when compared to those in Fig. 4(b). They grow onto the platinum terrace atoms located on the intermediate height in Fig. 4(c) and form the first $\mathrm{FeO}$ layer thereon. When compared to the lower coverage in Fig. 4(b), more $\mathrm{FeO}$ has also grown onto platinum atoms located one layer deeper than the platinum terrace atoms at the intermediate height, meaning that more substrate atoms have been displaced from their former positions. As the growth proceeds, the whole platinum substrate gets covered by the overlayer. This situation is shown in the 1 $\times 1-\mu \mathrm{m}^{2}$ image in Fig. 4(d), where the coverage has reached 1 ML. If one compares Fig. 4(d) with the clean substrate surface in Fig. 4(a), the change of the substrate morphology upon the oxide monolayer formation at $1000 \mathrm{~K}$ becomes evident.
Only one $\mathrm{FeO}$ layer grows on $\mathrm{Pt}(111)$ at oxidation temperatures of $T=1000 \mathrm{~K}$, and no second $\mathrm{FeO}$ layer forms upon further iron deposition-oxidation cycles. Instead, $\mathrm{Fe}_{3} \mathrm{O}_{4}$ islands start to grow on the first $\mathrm{FeO}$ monolayer at this stage, which can be seen in the $1 \times 1-\mu \mathrm{m}^{2}$ image in Fig. 4(e). That no second $\mathrm{FeO}$ layer has grown under these conditions is demonstrated in Fig. 4(f), which displays an 1100 $\times 1100-\AA^{2}$ region of the same film. The first $\mathrm{FeO}(111)$ layer with its characteristic moire pattern appears on two different heights, which are separated by a monoatomic platinum substrate step underneath the overlayer. Besides the $\mathrm{Fe}_{3} \mathrm{O}_{4}$ islands only one $\mathrm{FeO}$ layer covers the substrate at this point as indicated by the small uncovered platinum areas marked by the arrows in Fig. 4(f). They are equivalent to the bare substrate regions in Fig. 4(c) discussed above. Therefore, the high-lying oxide island in Fig. 4(f) is the first $\mathrm{FeO}$ layer that grew directly onto the platinum substrate. This is further supported by the shapes of this island which differs from the hexagonal shape of second $\mathrm{FeO}$ layer islands in Fig. 3(c).

To summarize, at $1000 \mathrm{~K}$ oxidation temperature only 1 ML forming an $\mathrm{FeO}(111)$-like structure grows onto $\mathrm{Pt}(111)$, before $\mathrm{Fe}_{3} \mathrm{O}_{4}$ islands start to grow. The substrate morphology changes considerably under these conditions, which is associated with the displacement of platinum substrate atoms.

\section{E. $\mathrm{Fe}_{3} \mathrm{O}_{4}$ growth at $T=870 \mathrm{~K}$}

To grow thicker iron oxide films, larger amounts of iron were deposited in each cycle when compared to the growth of the first layers presented in the previous sections. This amount was restricted in order to assure good ordering of the oxide films. For an oxidation temperature of $870 \mathrm{~K}$ an amount corresponding to the iron quantity necessary to grow about $1 \mathrm{ML}$ of $\mathrm{FeO}$ at the same temperature was chosen. Consequently, it took a large number of growth cycles to form the thick $\mathrm{Fe}_{3} \mathrm{O}_{4}$ films presented in the following.

The $1 \times 1-\mu \mathrm{m}^{2}$ images in Fig. 5 display the iron oxide growth at an oxidation temperature of $870 \mathrm{~K}$ after about 2 $\mathrm{ML}$ of $\mathrm{FeO}$ were grown layer by layer. In Fig. 5(a), analogous to the 2.2-ML-thick FeO film shown in Fig. 3(f), the second $\mathrm{FeO}$ layer is completed and third $\mathrm{FeO}$ layer islands have formed. In addition, several $\mathrm{Fe}_{3} \mathrm{O}_{4}$ islands with nearly triangular basal planes can be seen now. They are 20-25 $\AA$ high and extend laterally over 2000 to $3000 \AA$. At this growth stage a LEED pattern like the one shown in Fig. 6 is observed. It is a superposition of the $\mathrm{FeO}(111) / \mathrm{Pt}(111)$ satellite LEED pattern and the $\mathrm{Fe}_{3} \mathrm{O}_{4}(111)$ LEED pattern shown in Fig. 1. Note the spot splitting of the brightest spots, a result of the different average interatomic distances within the oxygen (111) planes of the two oxides as discussed in Sec. III A. High-resolution LEED measurements reveal exactly the bulk lattice spacing of $\mathrm{Fe}_{3} \mathrm{O}_{4}$, and we conclude that (111)-oriented islands with the $\mathrm{Fe}_{3} \mathrm{O}_{4}$ bulk structure have formed.

Figure 5(b) shows the film after additional evaporationoxidation cycles. No increase in the number of $\mathrm{Fe}_{3} \mathrm{O}_{4}$ islands is observed, even after inspection of many images. Instead, the $\mathrm{Fe}_{3} \mathrm{O}_{4}$ islands have increased in size. Now they are 40-50 $\AA$ high and form almost perfect triangles with side lengths of $6000-7000 \AA$. Triangular-shaped islands rotated by $180^{\circ}$ against each other are found at the surface as can be 

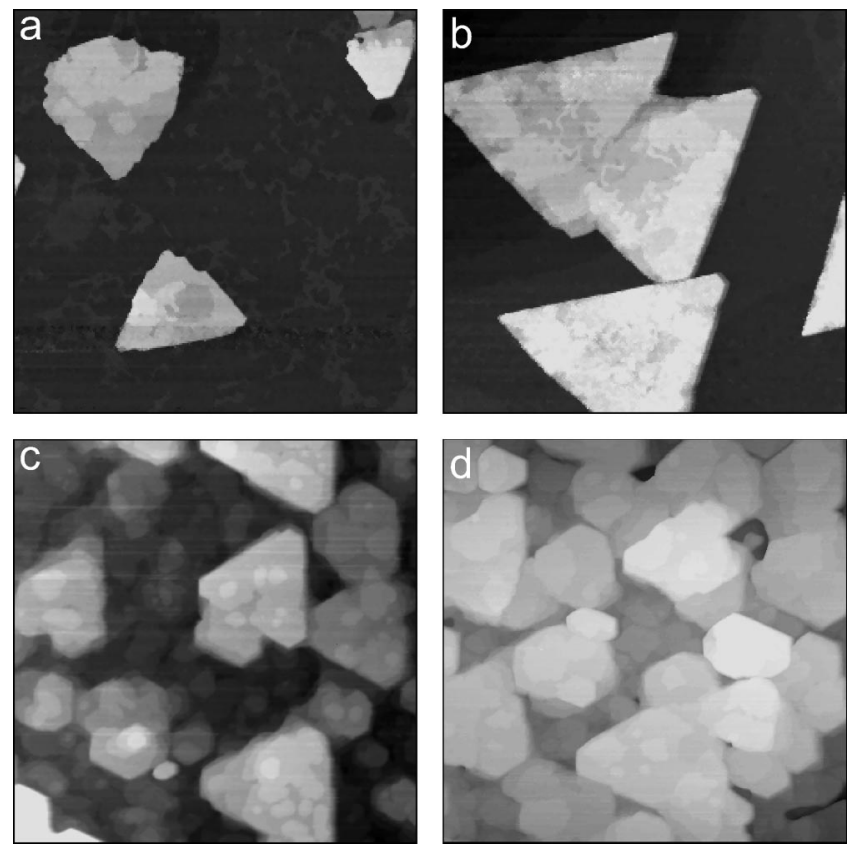

FIG. 5. $1 \times 1-\mu \mathrm{m}^{2}$ STM images of consecutive $\mathrm{Fe}_{3} \mathrm{O}_{4}(111)$ island growth stages for an oxidation temperature of $870 \mathrm{~K}$. Initially the number of islands does not increase but the island sizes do. The island heights range from 20 to $25 \AA$ in (a) and from 40 to $50 \AA$ in (b) and (c). In (c) new islands nucleate in between the large islands, in (d) all islands have coalesced forming a $\mathrm{Fe}_{3} \mathrm{O}_{4}(111)$ multilayer film at least $150 \AA$ thick.

seen on the right border of the image in Fig. 5(b). The side edges of the islands run along the $[\overline{1} 10]$ and $[01 \overline{1}]$ directions of the platinum substrate and the $\mathrm{Fe}_{3} \mathrm{O}_{4}(111)$ surface as known from high-resolution STM images. Some islands have coalesced already at this stage. The island surfaces exhibit high step densities with terraces 100-300 ̊ wide. The step height is mostly $5 \AA$, which corresponds to the distance between equivalent (111) surface terminations of $\mathrm{Fe}_{3} \mathrm{O}_{4}$. As the growth proceeds new small islands with hexagonal shapes start to grow in between and on top of the large

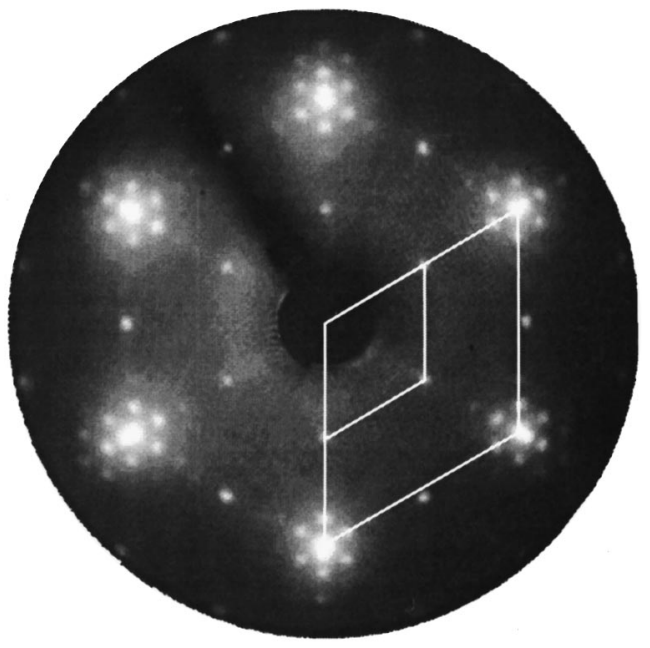

FIG. 6. LEED pattern of island films at $E=60 \mathrm{eV}$. It is a superposition of the $\mathrm{FeO}(111) / \mathrm{Pt}(111)$ and the $\mathrm{Fe}_{3} \mathrm{O}_{4}(111)$ LEED patterns shown in Figs. 1(b) and 1(c), respectively. The corresponding reciprocal unit cells are indicated.
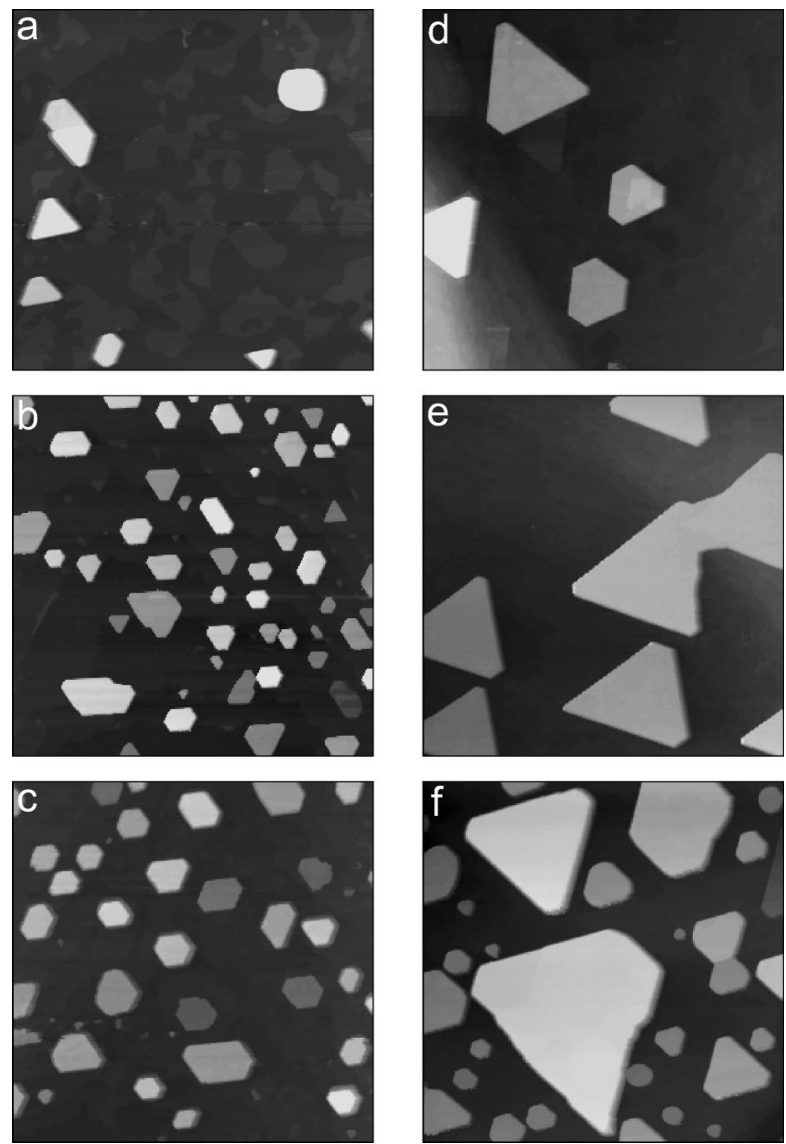

FIG. 7. $1 \times 1-\mu \mathrm{m}^{2}$ STM images of consecutive $\mathrm{Fe}_{3} \mathrm{O}_{4}$ island growth stages for an oxidation temperature of $1000 \mathrm{~K}$. In (a)-(c) the iron deposition rate was the same as for the films in Fig. 5. The islands do not exceed lateral dimensions of $2000 \AA$, their heights range from 25 to $70 \AA$. In (d)-(f) the iron deposition rate was ten times larger. The islands increase in size but not in number, until new small islands grow in between the large ones. The island heights range from 35 to $60 \AA$ in (d), 40 to $70 \AA$ in (e), and 25 to $100 \AA$ in (f).

triangular-shaped $\mathrm{Fe}_{3} \mathrm{O}_{4}$ islands, which can be seen in Fig. 5(c). These new islands also increase in size and eventually coalesce, until the whole substrate surface is covered by a thick $\mathrm{Fe}_{3} \mathrm{O}_{4}$ film as shown in Fig. 5(d). From the deposited amount of iron and from the island heights we estimate this film to be at least $150 \AA$ thick. It can be grown thicker by further iron deposition-oxidation cycles. The $\mathrm{FeO}(111)$ satellite LEED pattern has vanished and the $\mathrm{Fe}_{3} \mathrm{O}_{4}(111)$ LEED pattern shown in Fig. 1(c) is observed at this point.

\section{F. $\mathrm{Fe}_{3} \mathrm{O}_{4}$ growth at $T=1000 \mathrm{~K}$}

The $1 \times 1-\mu \mathrm{m}^{2}$ images in Fig. 7 display the iron oxide growth for an oxidation temperature of $1000 \mathrm{~K}$, after a complete $\mathrm{FeO}(111)$ monolayer has grown onto the $\mathrm{Pt}(111)$ surface. For all growth stages shown in Fig. 7 LEED patterns as shown in Fig. 6 are observed, indicating the formation of $\mathrm{Fe}_{3} \mathrm{O}_{4}(111)$ islands. The islands form crystallites with straight side edges and triangular or hexagonal shapes, depending on the growth stage and exact growth conditions. They are atomically flat with very few steps $5 \AA$ high, which indicates the existence of only one $\mathrm{Fe}_{3} \mathrm{O}_{4}(111)$ surface ter- 
mination. The island side edges run along the [110] and [011] directions of $\mathrm{Fe}_{3} \mathrm{O}_{4}(111)$. Due to the finite aspect ratio of the STM tip we could not determine the exact slope of the island side facets. Assuming all islands to form equivalent crystallites, we can exclude island side facets with slopes less than $70^{\circ}$, because we measured this slope for neighboring facets of hexagonal islands and for facets of triangular islands. A slope of $90^{\circ}$ corresponds to a vertical side facet.

In Figs. 7(a)-7(c) the amount of iron deposited in each cycle is about the same as for the films grown at $T=870 \mathrm{~K}$ presented in the preceding section. At the beginning in Fig. 7(a), hexagonal and some triangular-shaped islands with heights between 25 and $60 \AA$ and lateral dimensions around $1000 \AA$ have formed. Triangular islands rotated by $180^{\circ}$ also can be seen. After additional deposition-oxidation cycles in Fig. 7(b) the number of islands has increased, but not their sizes. Only the island heights have increased a little, now they range from 25 to $70 \AA$ A. More hexagonal-shaped islands have formed now. The number and size of islands does not change any more after further iron deposition-oxidation cycles, which can be seen in Fig. 7(c). No island coalescence is observed, and no closed $\mathrm{Fe}_{3} \mathrm{O}_{4}$ films covering the entire substrate surface are obtained under these growth conditions.

Figures 7(c)-7(f) display the $\mathrm{Fe}_{3} \mathrm{O}_{4}$ island growth at 1000 $\mathrm{K}$ oxidation temperature with an amount of iron deposited before each oxidation cycle increased by a factor of 10 when compared to Figs. 7(a)-7(c). At the beginning in Fig. 7(d), two small islands with hexagonal shape and two large islands with triangular shape rotated by $180^{\circ}$ against each other can be seen. The island heights range from 35 to $60 \AA$ at this point. After further growth in Fig. 7(e), the islands have become larger laterally and vertically. Now the heights range from 40 to $70 \AA$. Only triangular and no hexagonal-shaped islands exist at this growth stage. Upon further depositionoxidation cycles in Fig. 7(f), some islands have coalesced, forming the largest one in this image, and new small islands start to grow in between the large islands. The small islands are 25-60 ̊ high, the large ones $80-100 \AA$. This growth behavior is similar to the one observed for $870 \mathrm{~K}$ oxidation temperature and a smaller amount of iron deposited in each cycle. However, here for $T=1000 \mathrm{~K}$ no completely closed $\mathrm{Fe}_{3} \mathrm{O}_{4}$ films can be obtained either. But $\mathrm{Fe}_{3} \mathrm{O}_{4}$ films that cover the entire substrate can be grown at slightly lower oxidation temperatures of $920 \mathrm{~K}$, which will be shown in the next section.

\section{G. Morphology of $\mathrm{Fe}_{3} \mathrm{O}_{4}$ and $\alpha-\mathrm{Fe}_{2} \mathrm{O}_{3}$ multilayer films}

Figure 8 shows $1 \times 1-\mu \mathrm{m}^{2}$ images of three $\mathrm{Fe}_{3} \mathrm{O}_{4}(111)$ (a)-(c) films and of an $\alpha-\mathrm{Fe}_{2} \mathrm{O}_{3}(0001)$ film (d). Below, cross sections along the white lines in the images are displayed. The film in Fig. 8(a) was grown at $T=870 \mathrm{~K}$ oxidation temperature. Islands $2000-4000 \AA$ in diameter and smaller islands in between have coalesced, resulting in a film that is at least $150 \AA$ thick over the entire substrate. It has a mesoscopic surface roughness of about $40 \AA$ on the length scale of $1 \mu \mathrm{m}$ and a high step density with terrace widths between 50 and $500 \AA$. Most steps are $5 \AA$ high, indicating the dominance of one $\mathrm{Fe}_{3} \mathrm{O}_{4}(111)$ surface termination. After annealing this film for $15 \mathrm{~min}$ at $1000 \mathrm{~K}$ in $10^{-6}$ mbar oxygen the image shown in Fig. 8(b) was obtained. Now the surface step density has decreased considerably, and atomically flat terraces more than $1000 \AA$ wide are separated by steps $5 \AA$ or multiples thereof high. The LEED spots have become sharper and the background intensity has decreased also indicating fewer atomic surface defects. Several screw dislocations can be seen; two are marked by arrows in Fig. 8(b). However, as seen in the cross section, the mesoscopic surface roughness has not changed when compared to the film prior to the postannealing procedure in Fig. 8(a).

In the preceding section we have shown that no closed films are obtained for oxidation temperatures of $1000 \mathrm{~K}$. Closed films are obtained for slightly lower oxidation temperatures of $920 \mathrm{~K}$, as shown in Fig. 8(c). Here the morphology differs significantly from the morphologies of the films in Figs. 8(a) and $8(\mathrm{~b})$. The entire substrate is covered by mostly hexagonal-shaped crystallites $1000-2000 \AA$ in diameter. They form a closed $\mathrm{Fe}_{3} \mathrm{O}_{4}$ film with a mesoscopic surface roughness of about $100 \AA$ on a length scale of $1 \mu \mathrm{m}$. The crystalline surfaces are atomically flat with $1000-\AA$-wide terraces and steps $5 \AA$ or multiples thereof high, again indicating the existence of one $\mathrm{Fe}_{3} \mathrm{O}_{4}(111)$ surface termination only. The terrace widths decrease rapidly towards the crystal edges, where a step bunching is observed, which is not resolved in the cross section of Fig. 8(c). The morphology of these films did not change upon a postannealing procedure for $15 \mathrm{~min}$ at $T=1000 \mathrm{~K}$ in $10^{-6}$ mbar oxygen. More iron deposition-oxidation cycles were necessary to obtain such closed films when compared to the lower oxidation temperature of $870 \mathrm{~K}$, and we conclude a somewhat larger thickness of these films upon island coalescence.

Figure 8(d) shows an $\alpha-\mathrm{Fe}_{2} \mathrm{O}_{3}$ film after transformation of the $\mathrm{Fe}_{3} \mathrm{O}_{4}$ (111) film in Fig. 8(b) by a high-pressure oxidation as described in Sec. II. The $\mathrm{Fe}_{3} \mathrm{O}_{4}(111)$ LEED pattern in Fig. 1(c) has vanished upon the high-pressure treatment and the LEED pattern shown in Fig. 1(d) was obtained. This pattern corresponds to an unreconstructed (0001) surface termination of $\alpha-\mathrm{Fe}_{2} \mathrm{O}_{3}$ as discussed in Sec. III A. The hexagonal oxygen (0001) planes are aligned to those of the former $\mathrm{Fe}_{3} \mathrm{O}_{4}(111)$ film and to the $\mathrm{Pt}(111)$ surface lattice as indicated on the right side of Fig. 1. The mesoscopic surface roughness has almost not changed and is now about $50 \AA$ on a length scale of $1 \mu \mathrm{m}$. Although the LEED pattern of this film was of good quality, only a few atomically flat terraces were observed, which is evident in the cross section of Fig. $8(\mathrm{~d})$. For higher oxidation temperatures of about $1120 \mathrm{~K}$, atomically flat terraces up to $500 \AA$ wide developed. Domains exposing two different terminations were observed on these terraces in agreement with the predictions of ab initio density functional calculations. ${ }^{35}$ Equivalent $\alpha$ - $\mathrm{Fe}_{2} \mathrm{O}_{3}(0001)$ terminations are supposed to be separated by steps $2.3 \AA$ or multiples thereof high. This step height was frequently observed on these films.

\section{DISCUSSION}

If heteroepitaxial growth takes place close to equilibrium conditions, the growth mode depends on the surface free energies of the substrate $\gamma_{s}$ and the film $\gamma_{f}$ as well as on the interfacial energy $\gamma_{\text {in }} \cdot{ }^{36}$ The interfacial energy $\gamma_{\text {in }}$ contains the so-called zero strain contribution which depends on the specific chemical interaction between film and substrate at- 

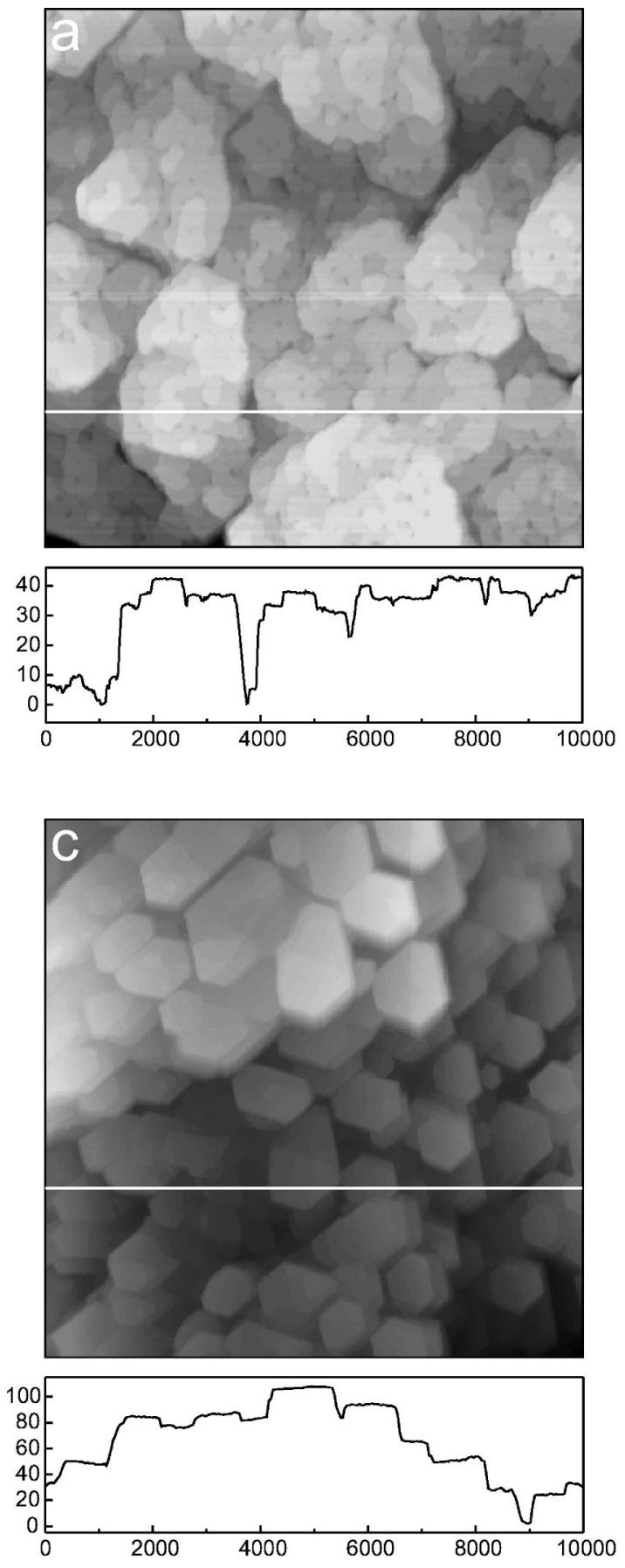
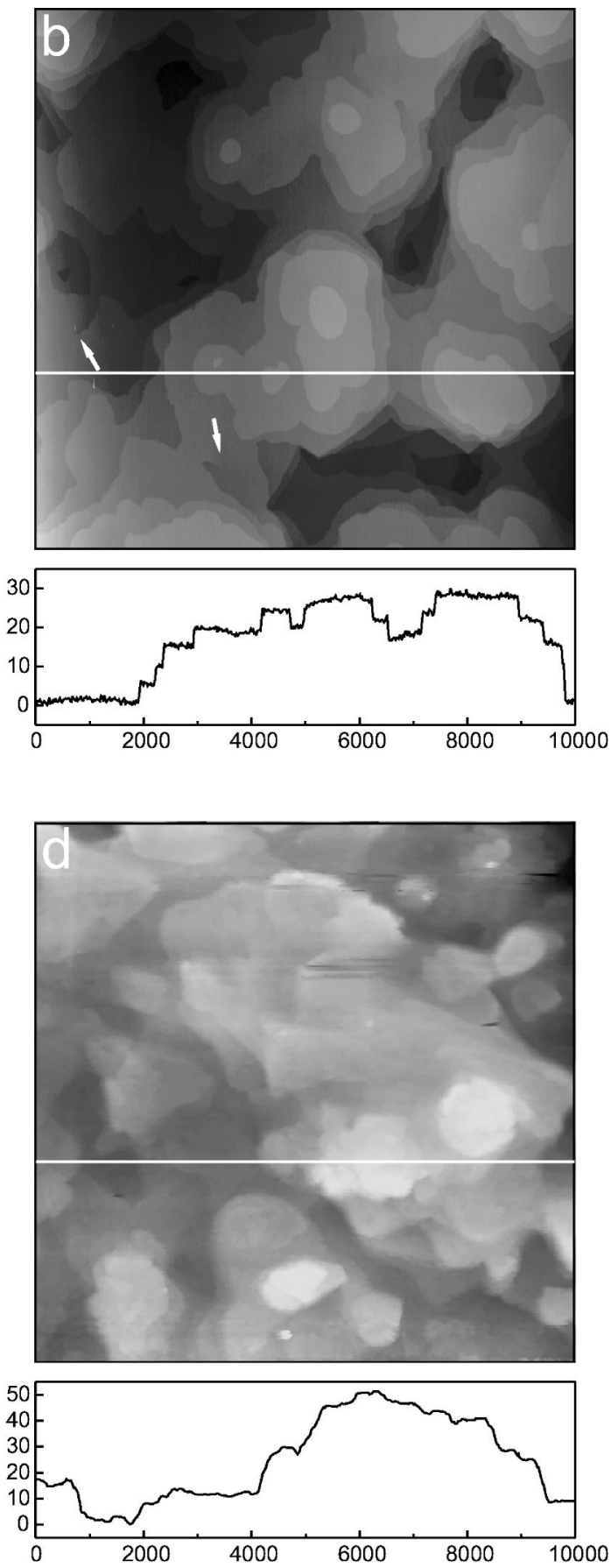

FIG. 8. $1 \times 1-\mu \mathrm{m}^{2}$ STM images of closed iron oxide films at least $150 \AA$ thick. Below cross sections along the white lines are shown, where the length scales are given in $\AA$. The $\mathrm{Fe}_{3} \mathrm{O}_{4}(111)$ film in (a) was grown at $T=870 \mathrm{~K}$. Postannealing of this film to $T=1000 \mathrm{~K}$ creates the film shown in (b), where the white arrows mark screw dislocations. (d) shows this film after transformation into an $\alpha$ - $\mathrm{Fe}_{2} \mathrm{O}_{3}(0001)$ film by oxidation at $p\left(\mathrm{O}_{2}\right)=10^{-6}$ mbar. The $\mathrm{Fe}_{3} \mathrm{O}_{4}(111)$ film in (c) was grown at $T=920 \mathrm{~K}$.

oms. It rapidly approaches zero with increasing distance from the interface and therefore is almost independent of the film thickness (depending on the range of the interatomic forces). When a material grows pseudomorphically onto a lattice-mismatched substrate, $\gamma_{\text {in }}$ also contains the elastic energy which increases linearly with film thickness. The surface energy of the strained film $\gamma_{f}$ deviates somewhat from the value of the corresponding semi-infinite crystal due to the surface strain. For ionic materials this deviation might be important since it is additionally caused by the electrostatic contribution to the surface free energy, which depends on the film thickness. In the general case of nonzero misfit, strict layer-by-layer growth (Frank-van der Merve mode) is only possible if $\Delta \gamma_{n}=\gamma_{f}+\gamma_{\text {in }}-\gamma_{s}<0$ for all $n$ ( $n$ is the number of atomic layers of the growing film). If $\Delta \gamma_{n}>0$ already for the first layer $n=1$, a three-dimensional film growth takes place from the beginning (Volmer-Weber mode). If $\Delta \gamma_{n}$ $>0$ for $n>1$ the first $n-1$ layers grow layer by layer before 
a three-dimensional growth starts. This growth mode is called the Stranski-Krastanov mode, where similar surface free energies of the wetting layer(s) and the island facets can be assumed. Then, the interfacial energy is the driving force for the island formation, and depending on the island size and on the interface/surface energies dislocated unstrained or coherently strained islands can form on top of the first wetting layers. ${ }^{37}$ If the large activation energy for the formation of dislocations at the interface can be overcome, dislocated islands without strain grow, ${ }^{38}$ and their growth can be described by an Ostwald ripening mechanism, which was formulated theoretically by Lifschitz and Slyozov ${ }^{39}$ and Wagner ${ }^{40}$ for crystal growth in supersaturated solutions and extended later to epitaxial island growth on substrates by Chakraverty. $^{41,42}$

\section{A. Fe growth}

Iron grows in the Volmer-Weber mode onto $\mathrm{Pt}(111)$. Most likely a $\gamma-\mathrm{Fe}(111)$ form is stabilized at the substrate as discussed in Sec. III B. This growth mode can be rationalized considering the surface free energies of Pt and Fe. Calculations by Mezey and Giber revealed much larger surface energies for $\alpha$-Fe than for Pt both at room temperature and at the corresponding melting temperatures. ${ }^{43}$ For $\gamma$-Fe a slightly smaller surface free energy $\left(2.15 \mathrm{~J} \mathrm{~m}^{-2}\right)$ was measured ${ }^{44}$ than for $\mathrm{Pt}$ (2.34 $\mathrm{J} \mathrm{m}^{-2}$ ) (Ref. 45) at temperatures around $1600 \mathrm{~K}$, which would allow a layer-by-layer growth for $\gamma-\mathrm{Fe}$ on $\operatorname{Pt}(111)$. However, one also has to consider the interfacial energy $\gamma_{\text {in }}$ of a pseudomorphic $\gamma$-Fe(111) film strained by $8 \%$. As strain values of a few percent cause significant elastic energies in this context, ${ }^{46}$ this explains the experimentally observed Volmer-Weber growth mode for this system.

\section{B. Initial iron oxide growth}

Iron oxide starts to grow as $\mathrm{FeO}(111)$ bilayers which are laterally slightly expanded if compared to bulk FeO. However, this is not a pseudomorphic growth because the $\mathrm{FeO}(111)$ overlayer lattice $[3.1 \AA$ interatomic distance within the (111) planes] does not accommodate to the platinum substrate lattice $[2.77 \AA$ interatomic distance within the (111) planes]. Instead, specific coincidence structures are formed at the substrate-overlayer interface. ${ }^{32}$

The FeO overlayer completely wets the platinum surface. The surface free energy of most metal oxides is considerably lower than that of platinum; for $\mathrm{FeO} 0.6 \mathrm{~J} / \mathrm{m}^{2}$ was reported. ${ }^{47}$ This suggests the observed wetting behavior although a monolayer film does not represent an $\mathrm{FeO}$ bulk material. It also explains the layer-by-layer growth of the first FeO layers observed for an oxidation temperature of $870 \mathrm{~K}$. Since $\mathrm{FeO}$ is thermodynamically not stable at our preparation conditions $\left[T=870-1000 \mathrm{~K}\right.$ and $\left.p\left(\mathrm{O}_{2}\right)=10^{-6} \mathrm{mbar}\right],{ }^{20}$ the $\mathrm{FeO}$ films represent a metastable phase that is initially stabilized by the interaction between the platinum substrate and the overlayer at the interface. They can only grow up to $2.5 \mathrm{ML}$ thickness, where the third FeO layer growth is strongly hindered as indicated by its morphology. While second $\mathrm{FeO}$ layer islands form hexagons with small side edge length/ surface area ratios in the initial stage [Fig. 3(c)], which is energetically favorable, ${ }^{37}$ the third FeO layer islands do not [Fig. 3(f)]. An increasing surface free energy with increasing
FeO layer thickness might prevent these films from becoming thicker. For the elevated oxidation temperature of 1000 $\mathrm{K}$ no second $\mathrm{FeO}$ layer can be stabilized any more and the formation of $\mathrm{Fe}_{3} \mathrm{O}_{4}$ islands becomes favorable.

Furthermore, at this elevated oxidation temperature a substantial roughening of the Pt substrate is observed. This is due to the mobility of the platinum atoms which increases strongly on $\mathrm{Pt}(111)$ at temperatures above $700 \mathrm{~K}^{48}$ Also diffusion of iron atoms into the platinum substrate at these elevated temperatures, as observed by Vurens et al., ${ }^{49}$ contributes to the substrate roughening, which was also reported by Bertrams and Neddermeyer after the growth of $\mathrm{NiD}(100)$ films on $\mathrm{Ag}(100)$ and postannealing to $T=470 \mathrm{~K}$. $^{50}$

\section{Continued iron oxide growth}

\section{1. $\mathrm{Fe}_{3} \mathrm{O}_{4}$ island formation}

After 1-2-ML-thick $\mathrm{FeO}(111)$ films have formed, which completely wet the platinum substrate surface, a threedimensional growth of $\mathrm{Fe}_{3} \mathrm{O}_{4}$ islands begins. This results in a Stranski-Krastanov growth mode for iron oxides on $\operatorname{Pt}(111)$ if we expand this growth mode terminus to the present case with two different oxide phases involved, $\mathrm{FeO}$ and $\mathrm{Fe}_{3} \mathrm{O}_{4}$, which have closely related crystal structures. The iron oxide growth is depicted schematically in Fig. 9. The island formation starts earlier with respect to the $\mathrm{FeO}$ film thickness for higher oxidation temperatures. This is presumably due to the higher mobility of iron oxide at elevated temperatures, which accelerates the formation of $\mathrm{Fe}_{3} \mathrm{O}_{4}(111)$ islands, that are always at least $20 \AA$ high. From the LEED pattern in Fig. 6 it follows that the hexagonal oxygen (111) planes in the $\mathrm{Fe}_{3} \mathrm{O}_{4}$ magnetite structure are aligned to those of the hexagonal $\mathrm{Pt}(111)$ surface lattice and to those of the first $\mathrm{FeO}(111)$ layers, as displayed in Fig. 1. High-resolution LEED measurements revealed the $\mathrm{Fe}_{3} \mathrm{O}_{4}$ bulk lattice constant for the islands observed in this work. ${ }^{32}$

Although we cannot rule out the transformation of the first $\mathrm{FeO}$ layers into $\mathrm{Fe}_{3} \mathrm{O}_{4}$ underneath the islands, which would result in a three-dimensional growth of $\mathrm{Fe}_{3} \mathrm{O}_{4}$ directly onto $\mathrm{Pt}(111)$, we assume the $\mathrm{Fe}_{3} \mathrm{O}_{4}(111)$ islands to grow on the first $\mathrm{FeO}(111)$ layer since the latter is very stable as deduced from thermal desorption experiments. ${ }^{51}$ This results in an oxide on oxide growth, where the oxygen sublattice mismatch dominates the interfacial energy as observed by several studies. A layer-by-layer growth was observed in the case of small lattice mismatches, for example, for $\mathrm{Fe}_{3} \mathrm{O}_{4}(001)$ on $\mathrm{MgO}(001)$ (Ref. 11) and for $\mathrm{Fe}_{3} \mathrm{O}_{4}(110)$ on $\mathrm{MgO}(110)(0.3 \%$ mismatch $){ }^{8}$ whereas an island growth mode was observed for $\mathrm{Fe}_{3} \mathrm{O}_{4}(111)$ on $\mathrm{Al}_{2} \mathrm{O}_{3}(0001)$ (Refs. 52 and 9) (8.4\% lattice mismatch). The mismatch between the (111) oxygen planes of $\mathrm{Fe}_{3} \mathrm{O}_{4}$ and the underlying $\mathrm{FeO}$ film is $4 \%$, which induces the observed island growth if we assume similar surface energies for the two oxide phases. As the $\mathrm{Fe}_{3} \mathrm{O}_{4}$ grows in its bulk structure, it forms dislocated unstrained islands. Our oxidation temperatures seem to provide the activation energy necessary to form dislocations at the $\mathrm{FeO}(111) / \mathrm{Fe}_{3} \mathrm{O}_{4}(111)$ interface, which can release the stress within the growing islands.

According to the iron-oxygen bulk phase diagram ${ }^{20}$ the formation of $\alpha-\mathrm{Fe}_{2} \mathrm{O}_{3}$ instead of $\mathrm{Fe}_{3} \mathrm{O}_{4}$ is expected for the preparation conditions used here $\left[p\left(\mathrm{O}_{2}\right)=10^{-6}\right.$ mbar, $T$ 

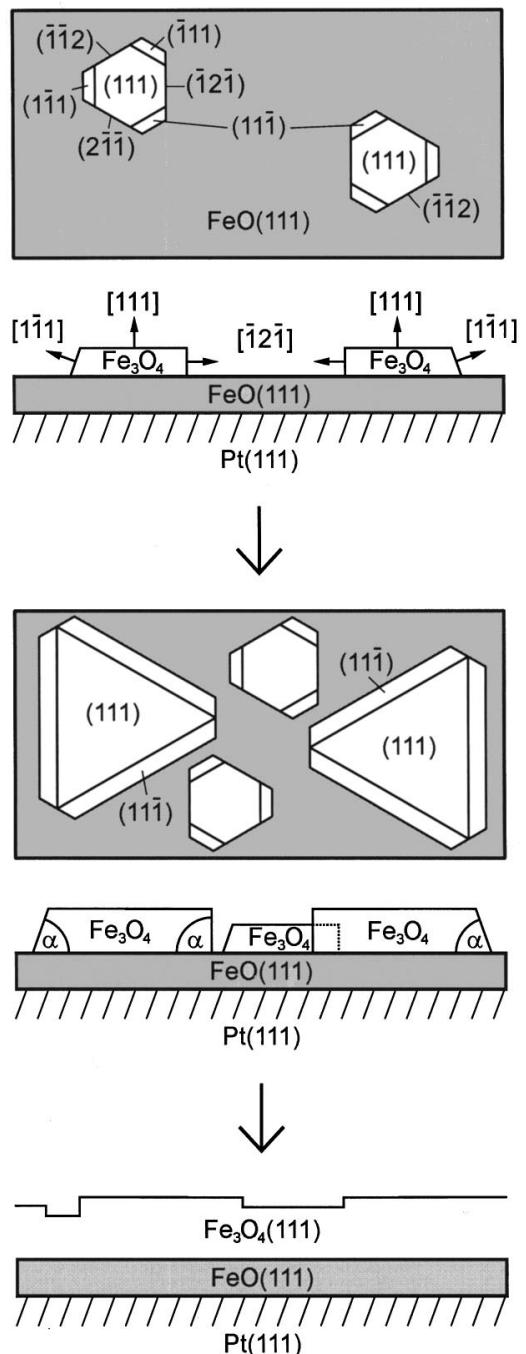

$\mathrm{Pt}(111)$

FIG. 9. Schematic representation of the Stranski-Krastanov growth for iron oxides on $\mathrm{Pt}(111)$. The island surface and facet plane orientations are indicated.

$=870-1000 \mathrm{~K}]$. The $\mathrm{Fe}_{3} \mathrm{O}_{4}$ formation must be due to the short oxidation time of $2 \mathrm{~min}$, as the oxidation of $\mathrm{Fe}_{3} \mathrm{O}_{4}$ to $\alpha-\mathrm{Fe}_{2} \mathrm{O}_{3}$ is a slow process. After annealing $\mathrm{Fe}_{3} \mathrm{O}_{4}(111)$ multilayer films for several hours at our $\mathrm{Fe}_{3} \mathrm{O}_{4}$ growth conditions a film consisting of both $\mathrm{Fe}_{3} \mathrm{O}_{4}$ and $\alpha$ - $\mathrm{Fe}_{2} \mathrm{O}_{3}$ phases was detected by LEED. That the oxidation kinetics determines the iron oxide phase formed during epitaxial growth was also observed by Kim et al., who demonstrated that the selective growth of $\mathrm{Fe}_{3} \mathrm{O}_{4}$ and $\alpha$ - $\mathrm{Fe}_{2} \mathrm{O}_{3}$ films depends on the growth rate and oxygen pressure during oxygen-plasmaassisted molecular-beam epitaxy. High growth rates and low oxygen pressures were required to obtain $\mathrm{Fe}_{3} \mathrm{O}_{4}$, while low growth rates and high oxygen pressures were needed to obtain $\alpha-\mathrm{Fe}_{2} \mathrm{O}_{3}{ }^{10}$

\section{2. $\mathrm{Fe}_{3} \mathrm{O}_{4}$ island facets}

We observe large islands with mostly triangular basal planes and small islands with mostly hexagonal basal planes as indicated in Fig. 9. Our STM measurements reveal the contact angle $\alpha$ between the substrate surface and the facet planes to be at least $70^{\circ}$. To determine the possible orienta- tions of the island facets, we consider low index planes with contact angles less than $90^{\circ} .\{100\}$ planes can be ruled out because they have contact angles of $55^{\circ}$ and $125^{\circ}$. The most stable surfaces of magnetite are the $\{111\}$ and $\{110\}$ planes, leading to octahedral and rhombodecahedral macroscopic crystal forms. ${ }^{19}$ As known from atomic resolution STM images measured on the island surfaces, the island edges run parallel to the atomic rows on the $\mathrm{Fe}_{3} \mathrm{O}_{4}(111)$ surface, i.e., along the $[\overline{1} 10]$ and $[01 \overline{1}]$ directions indicated in Fig. 1(c). $\{110\}$ planes that are compatible with these side edges are the (110) and (110) planes and those obtained by the $p 3 m 1$ symmetry of the $\mathrm{Fe}_{3} \mathrm{O}_{4}(111)$ surface. However, they can also be ruled out since they have contact angles of $35^{\circ}$ and $145^{\circ}$, respectively. We attribute three of the six island facets to (111) planes and symmetrically equivalent ones as indicated in Fig. 9, because they form an angle $\alpha$ of $70.5^{\circ}$ to the substrate surface as well as the observed island edge directions. The next stable low index surface planes of magnetite are the $\{112\}$ planes, and we attribute $(2 \overline{1} \overline{1})$ planes to the other three facets of the hexagonal-shaped islands as indicated in Fig. 9. These facets form a contact angle of $90^{\circ}$ as well as island edges along the atomic rows we observed.

\section{3. $\mathrm{Fe}_{3} \mathrm{O}_{4}$ island growth mechanism}

We do not observe an influence of substrate defects on the island formation. Therefore we assume a homogeneous nucleation mechanism, which takes place during each oxidation cycle following the iron deposition at room temperature. A supersaturated solution of iron or of an oxide precursor is generated on top of the $\mathrm{FeO}(111)$ films, resulting in a uniform nucleation probability all over the $\mathrm{FeO}(111)$ surface. As presented in Secs. III E and IIIF, three different island growth scenarios were observed depending on the growth conditions. The growth at $870-\mathrm{K}$ oxidation temperature shall be called regime 1 (Fig. 5). In regime 2 the oxidation temperature was $1000 \mathrm{~K}$ [Figs. 7(a)-7(c)]. In regime 3 the oxidation temperature also was $1000 \mathrm{~K}$, but the amount of iron deposited in each growth cycle was one order of magnitude higher than in the other two regimes [Figs. 7(d)-7(f)]. In all regimes the islands grow laterally much faster than vertically. The aspect ratio of the islands (height/basal plane diameter) increases with increasing oxidation temperature, indicating an additional activation energy for the upward diffusion of iron oxide on the island facets. At the higher oxidation temperature in regimes 2 and 3 there is a higher iron mobility, which leads to less rough island surfaces and more straight island edges in comparison to regime 1 .

Most small islands with diameters below $2000 \AA$ are hexagonal shaped, all larger islands are triangular shaped. If a crystal is in equilibrium with its vapor phase, the total surface free energy is minimized ${ }^{53}$ and the equilibrium crystal shape can be obtained by the Wulff construction, provided the relevant surface free energies are known. ${ }^{54}$ However, if a crystal grows from a supersaturated solution the growth shape of the crystal generally deviates from its equilibrium shape. The growth velocity perpendicular to a crystal plane increases with the corresponding surface free energy, the fast growing $(2 \overline{1} \overline{1})$ planes eventually disappear, and only the slow growing stable ( $\overline{1} 11)$ surface planes remain. ${ }^{55}$ The hexagonal islands might be close to the equilibrium shape of the 
magnetite crystallites. Upon further island growth, however, the less stable $(2 \overline{1} \overline{1})$ facets disappear until the large triangular islands expose only the more stable (111) facets, as indicated in Fig. 9. The formation of triangular-shaped islands rotated by $180^{\circ}$ indicates the existence of two in-plane orientations of $\mathrm{Fe}_{3} \mathrm{O}_{4}(111)$ related by a $180^{\circ}$ rotation about the [111] axes. This is in line with LEED measurements on these films that sometimes revealed a sixfold rotational symmetry of the LEED pattern. This symmetry can only be explained by $180^{\circ}$ domain orientations being simultaneously present at the surface since the $\mathrm{Fe}_{3} \mathrm{O}_{4}(111)$ surface has a threefold rotational symmetry. The second domain orientation also creates a corresponding second epitaxial relationship. Such rotational twinning has also been observed for systems like $\mathrm{Pt}(111)$ on $\alpha-\mathrm{Al}_{2} \mathrm{O}_{3}(0001)$ (Ref. 56) and $\mathrm{Fe}_{3} \mathrm{O}_{4}(111)$ on $\alpha-\mathrm{Al}_{2} \mathrm{O}_{3}(0001) .{ }^{9} \mathrm{It}$ is a natural growth mode for (111) films of fcc crystals and is caused by the random occurrence of $A B C A B C$ and $A C B A C B$ stacking sequences, which presumably has a minor effect on the interfacial energy or nucleation probability.

In all three regimes similar numbers of islands are formed at the beginning as expected for a homogeneous nucleation mechanism, which takes place in the oxide precursor solution formed by the iron deposited onto $\mathrm{FeO}(111)$. In regimes 1 and 3 these islands increase in size but not much in numbers upon further growth cycles, which is due to an Ostwald ripening mechanism: ${ }^{39-41}$ During each oxidation cycle new small islands nucleate from the supersaturated oxide precursor solution in between the larger islands that have already formed. As a result of the Gibbs-Thomson relation ${ }^{40}$ the small islands have a larger solubility in the surrounding precursor solution. This results in a material transport from the small to the large islands leading to dissolution of the small islands again. In this way the large islands grow at the expense of the small islands that nucleate and dissolve again during each oxidation cycle, and an increase in size but not in number of the islands is observed. When the islands reach lateral sizes of $3000-5000 \AA$ and triangular shapes, new small islands start to form in between them. Since triangularshaped islands only expose ( $\overline{1} 11)$ facets with a small growth velocity perpendicular to these surface planes, the material transport to these large islands is slowed down. As a result small islands that nucleate during the following oxidation cycles do not dissolve any more within the 2 min oxidation time. The small islands in Fig. 7(c) exhibit round-shaped edges, which indicates that dissolution of these edges has started as a result of the ripening process.

A different scenario is observed in regime 2. Here the sizes of the initially formed islands do not increase any more upon further growth cycles, the number of islands increases at the beginning and stays constant later on. During each oxidation cycle the oxide precursor always gets removed from the regions in between the islands due to the oxide island growth. At the same time iron is lost from the surface by diffusion into the platinum substrate as well as by desorption into the gas phase. These two material loss channels are significant at temperatures around $T=1000 \mathrm{~K}$ as observed by ion scattering spectroscopy (ISS) (Ref. 49) and mass spectrometry. ${ }^{51}$ Increasing amounts of iron oxide evaporate from the island surfaces into the gas phase with increasing total surface area of all islands. Because small amounts of iron were deposited, the precursor solution in between the islands vanishes very fast and only little ripening can take place, which at some point just balances the iron oxide loss due to evaporation from the island surfaces. When the situation in Fig. 7(b) or 7(c) is reached, no new islands can grow any more, since all islands that nucleate dissolve again. This results in the constant number and size of islands we observe here. At $870-\mathrm{K}$ oxidation temperature in regime 1 the material losses are smaller, the precursor solution is available longer, and more ripening can take place. In regime 3 with an oxidation temperature of $1000 \mathrm{~K}$ the material losses are the same as in regime 2, but since here a ten times larger amount of iron is deposited the precursor solution vanishes more slowly during the oxidation process, which allows the ripening observed. In Fig. 7(c) the total amount of iron deposited and the total oxidation time were higher than in Fig. 7(d), but nevertheless less ripening took place. This indicates that the material transport during ripening cannot simply take place by surface diffusion, but it needs the presence of the precursor solution.

\section{D. $\mathrm{Fe}_{3} \mathrm{O}_{4}$ and $\alpha$ - $\mathrm{Fe}_{2} \mathrm{O}_{3}$ multilayer films}

Considering the lateral and vertical dimensions of the $\mathrm{Fe}_{3} \mathrm{O}_{4}$ islands (3000-5000 and $100 \AA$, respectively), their morphology is described by flat platelets rather than by columns. For oxidation temperatures between 870 and $920 \mathrm{~K}$ these islands eventually coalesce and form closed and rather smooth films at least $150 \AA$ thick. These $\mathrm{Fe}_{3} \mathrm{O}_{4}(111)$ films can be transformed into $\alpha-\mathrm{Fe}_{2} \mathrm{O}_{3}(0001)$ films by a high-pressure oxidation. The orientations of all three oxide phases with respect to the platinum substrate are depicted in Fig. 1. Not considering the $180^{\circ}$ twinning domains, the epitaxial relationships with respect to the platinum substrate are $\mathrm{Fe}_{3} \mathrm{O}_{4}(111)[110] \| \mathrm{Pt}(111)[110]$ and $\alpha-\mathrm{Fe}_{2} \mathrm{O}_{3}(0001)[1 \overline{1} 00] \mid \operatorname{Pt}(111)[\overline{1} 10]$.

The atomic step densities on the films grown at $T$ $=870 \mathrm{~K}[$ Fig. $8(\mathrm{a})]$ decrease after a postannealing treatment to $T=1000 \mathrm{~K}$ in $10^{-6} \mathrm{mbar}$ oxygen, whereas no change occurs in this respect after postannealing the films grown at $T$ $=920 \mathrm{~K}$ [Fig. 8(c)]. This indicates that a stable $\mathrm{Fe}_{3} \mathrm{O}_{4}$ film morphology is established around $T=920 \mathrm{~K}$, which does not change any more at higher temperatures. The mesoscopic surface roughness on the $\mathrm{Fe}_{3} \mathrm{O}_{4}(111)$ films grown at $T$ $=870$ and $920 \mathrm{~K}$ in Figs. 8(b) and 8(c) differs by a factor of 3 , and the atomic step densities on these two films differ in a similar way. On the $\alpha-\mathrm{Fe}_{2} \mathrm{O}_{3}(0001)$ films the mesoscopic surface roughness is similar to the one on the respective $\mathrm{Fe}_{3} \mathrm{O}_{4}(111)$ films prior to the high-pressure oxidation, but the atomic step density becomes considerably higher. This high step density can be reduced somewhat by increasing the temperature during the high-pressure oxidation. This shows that the mesoscopic and atomic surface roughness can be controlled within a certain range by choosing the proper film growth and preparation conditions.

\section{SUMMARY}

The growth of epitaxial iron oxide films on $\mathrm{Pt}(111)$ surfaces accomplished by repeated cycles of iron deposition at 
room temperature and subsequent oxidation at elevated temperatures was studied by STM and LEED. Despite a $12 \%$ lattice mismatch the first layer forms a stable $\mathrm{FeO}(111) / \mathrm{Pt}(111)$ coincidence structure that completely wets the platinum substrate surface. For oxidation temperatures of $870 \mathrm{~K}$ second and third $\mathrm{FeO}(111)$ layers grow layer by layer, for oxidation temperatures of $1000 \mathrm{~K}$ only the first monolayer is formed. On top of these $\mathrm{FeO}(111)$ films a homogeneous nucleation of three-dimensional $\mathrm{Fe}_{3} \mathrm{O}_{4}(111)$ islands takes place, resulting in a Stranski-Krastanov growth mode for iron oxides on $\mathrm{Pt}(111)$. The islands are unstrained and form the $\mathrm{Fe}_{3} \mathrm{O}_{4}$ bulk structure. The $4 \%$ lattice mismatch to the underlying $\mathrm{FeO}(111)$ surface is released by dislocations at the interface. The $\mathrm{Fe}_{3} \mathrm{O}_{4}$ islands grow laterally much faster than vertically, thereby forming flat platelets with diameters of 2000-5000 $\AA$ and heights of $100 \AA$. They expose only stable low index $\{111\}$ and $\{211\}$ facet planes. The island growth can be explained by an Ostwald ripening mechanism taking place during each oxidation cycle. A mobile oxide precursor is formed from the deposited iron, the former acting as a supersaturated solution on top of the $\mathrm{FeO}(111)$ film, and allows a material transport between different islands. New $\mathrm{Fe}_{3} \mathrm{O}_{4}$ islands nucleate during each oxidation cycle and dissolve again due to their higher solubility when compared to larger islands, resulting in a further growth of large islands at the expense of the small islands.
For growth temperatures below $920 \mathrm{~K}$ the islands eventually coalesce and form closed $\mathrm{Fe}_{3} \mathrm{O}_{4}(111)$ films at least 150 $\AA$ thick. These multilayer films are rather smooth, and, depending on the growth temperature, their surface roughness ranges from 40 to $100 \AA$ on a length scale of $1 \mu \mathrm{m}$. The atomic step densities on these films also depend on the growth temperature and can be controlled within a certain range. Well-ordered $\alpha$ - $\mathrm{Fe}_{2} \mathrm{O}_{3}(0001)$ films were obtained by oxidizing the $\mathrm{Fe}_{3} \mathrm{O}_{4}$ films at oxygen pressures of $10^{-1}$ mbar. Their mesoscopic roughness is similar to those of the $\mathrm{Fe}_{3} \mathrm{O}_{4}$ films before transformation, but their atomic surface step density becomes much higher. This high step density can be reduced by increasing the temperature during the highpressure oxidation. The hexagonal oxygen (111) planes of all oxide phases formed are aligned to the $\mathrm{Pt}(111)$ substrate surface lattice resulting in the epitaxial relationships indicated in Fig. 1.

\section{ACKNOWLEDGMENTS}

The authors thank Shamil K. Shaikhutdinov for experimental support and R. Schlögl for helpful discussions. M.R. acknowledges financial support from the Deutsche Forschungsgemeinschaft.
${ }^{1}$ V. E. Henrich and P. A. Cox, The Surface Science of Metal Oxides (Cambridge University Press, Cambridge, England, 1994).

${ }^{2}$ Adsorption on Ordered Surfaces of Ionic Solids and Thin Films, edited by H.-J. Freund and E. Umbach, Springer Series in Surface Science Vol. 33 (Springer, Berlin, 1993).

${ }^{3}$ C. Noguera, Physics and Chemistry at Oxide Surfaces (Cambridge University Press, Cambridge, England, 1996).

${ }^{4}$ W. Weiss, D. Zscherpel, and R. Schlögl, Catal. Lett. 52, 215 (1998).

${ }^{5}$ H.-J. Freund, Angew. Chem. 109/5, 444 (1997).

${ }^{6}$ J. M. Gaines, P. J. H. Bloemen, J. T. Kohlhepp, C. W. T. Bulle-Lieuwma, R. M. Wolf, A. Reinders, R. M. Jungblut, P. A. A. van der Heijden, J. T. W. M. van Eemeren, J. aan de Stegge, and W. J. M. de Jonge, Surf. Sci. 373, 85 (1997).

${ }^{7}$ H. Hannemann, C. A. Ventrice, Th. Bertrams, A. Brodde, and H. Neddermeyer, Phys. Status Solidi 146, 289 (1994).

${ }^{8}$ F. C. Voogt, T. Hibma, G. L. Zhang, M. Hoefman, and L. Niesen, Surf. Sci. 331, 1508 (1995).

${ }^{9}$ Y. Gao, Y. J. Kim, and S. A. Chambers, J. Vac. Sci. Technol. A 15, 332 (1997)

${ }^{10}$ Y. J. Kim, Y. Gao, and S. A. Chambers, Surf. Sci. 371, 358 (1997).

${ }^{11}$ D. M. Lind, S. D. Berry, G. Chern, H. Mathias, and L. R. Testardi, Phys. Rev. B 45, 1838 (1992).

${ }^{12}$ A. B. Boffa, H. C. Galloway, P. W. Jacobs, J. J. Benitez, J. D. Batteas, M. Salmeron, A. T. Bell, and G. A. Somorjai, Surf. Sci. 326, 80 (1995)

${ }^{13}$ G. S. Hermann, M. C. Gallagher, S. A. Joyce, and C. H. F. Peden, J. Mater. Res. B14, 1126 (1996).

${ }^{14}$ W. Weiss, Surf. Sci. 377, 943 (1997).

${ }^{15}$ H. Brune, Surf. Sci. Rep. 31, 121 (1998).
${ }^{16}$ D. Schmalzried, Chemical Kinetics of Solids (VCH, Weinheim, 1995).

${ }^{17}$ J. W. Geus, Appl. Catal. 25, 313 (1986).

${ }^{18}$ T. Hirano, Appl. Catal. 26, 65 (1986).

${ }^{19}$ R. M. Cornell and U. Schwertmann, The Iron Oxides $(\mathrm{VCH}$, Weinheim, 1996).

${ }^{20}$ A. Muan, Am. J. Sci. 256, 171 (1958).

${ }^{21}$ G. H. Vurens, M. Salmeron, and G. A. Somorjai, Surf. Sci. 201, 129 (1988).

${ }^{22}$ G. H. Vurens, D. R. Strongin, M. Salmeron, and G. A. Somorjai, Surf. Sci. 199, L387 (1988).

${ }^{23}$ H. C. Galloway, J. J. Benitez, and M. Salmeron, Surf. Sci. 298, 127 (1993).

${ }^{24}$ H. C. Galloway, P. Sautet, and M. Salmeron, Phys. Rev. B 54, R11 145 (1996).

${ }^{25}$ Y. J. Kim, C. Westphal, R. X. Ynzunza, H. C. Galloway, M. Salmeron, M. A. Van Hove, and C. S. Fadley, Phys. Rev. B 55, R13 448 (1997).

${ }^{26}$ W. Weiss and G. A. Somorjai, J. Vac. Sci. Technol. A 11, 2138 (1993).

${ }^{27}$ W. Weiss, A. Barbieri, M. A. Van Hove, and G. A. Somorjai, Phys. Rev. Lett. 71, 1848 (1993).

${ }^{28}$ A. Barbieri, W. Weiss, M. A. Van Hove, and G. A. Somorjai, Surf. Sci. 302, 259 (1994).

${ }^{29}$ Y. Q. Cai, M. Ritter, W. Weiss, and A. M. Bradshaw, Phys. Rev. B 58, 5043 (1998).

${ }^{30}$ Th. Schedel-Niedrig, W. Weiss, and R. Schlögl, Phys. Rev. B 52, 17449 (1995).

${ }^{31}$ W. Weiss, M. Ritter, D. Zscherpel, M. Swoboda, and R. Schlögl, J. Vac. Sci. Technol. A 16, 21 (1998).

${ }^{32}$ M. Ritter, W. Ranke, and W. Weiss, Phys. Rev. B 57, 7240 (1998). 
${ }^{33}$ M. Wuttig, B. Feldmann, and T. Flores, Surf. Sci. 331, 659 (1995).

${ }^{34}$ U. Gradmann, W. Kümmerle, and P. Tillmanns, Thin Solid Films 34, 249 (1976).

${ }^{35}$ X.-G. Wang, W. Weiss, Sh. K. Shaikhutdinov, M. Ritter, M. Petersen, F. Wagner, R. Schlögl, and M. Scheffler, Phys. Rev. Lett. 81, 1038 (1998).

${ }^{36}$ E. Bauer and J. H. van der Merve, Phys. Rev. B 33, 3657 (1986).

${ }^{37}$ E. Pehlke, N. Moll, A. Kley, and M. Scheffler, Appl. Phys. A: Mater. Sci. Process. 65, 525 (1997).

${ }^{38}$ F. K. LeGoues, J. Tersoff, M. C. Reuter, M. Hammer, and R. Tromp, Appl. Phys. Lett. 67, 2317 (1995).

${ }^{39}$ I. M. Lifschitz and V. V. Slyozov, J. Phys. Chem. Solids 19, 35 (1961).

${ }^{40}$ C. Wagner, Z. Elektrochem. 65, 581 (1961).

${ }^{41}$ B. K. Chakraverty, J. Phys. Chem. Solids 28, 2401 (1967).

${ }^{42}$ B. K. Chakraverty, J. Phys. Chem. Solids 28, 2431 (1967).

${ }^{43}$ L. Z. Mezey and J. Giber, Jpn. J. Appl. Phys., Part 1 21, 1569 (1982).

${ }^{44}$ A. T. Price, A. H. Holl, and A. P. Greenough, Acta Metall. 12, 49 (1964)
${ }^{45}$ J. M. Blakely and H. Mykura, Acta Metall. 10, 565 (1962).

${ }^{46}$ A. Kobayashi and S. Das Sarma, Phys. Rev. B 35, 8042 (1987).

${ }^{47}$ S. H. Overbury, P. A. Bertrand, and G. A. Somorjai, Chem. Rev. 75, 547 (1975).

${ }^{48}$ T. Michely, T. Land, U. Littmark, and G. Comsa, Surf. Sci. 272, 204 (1992)

${ }^{49}$ G. H. Vurens, V. Maurice, M. Salmeron, and G. A. Somorjai, Surf. Sci. 268, 170 (1992).

${ }^{50}$ Th. Bertrams and H. Neddermeyer, J. Vac. Sci. Technol. B 14, 1141 (1996).

${ }^{51}$ D. Zscherpel, Ph.D. thesis, Freie Universität Berlin, 1998.

${ }^{52}$ T. Fujii, M. Takano, R. Katano, Y. Bando, and Y Isozumi, J. Appl. Phys. 666, 3168 (1989).

${ }^{53}$ J. W. Gibbs, Trans. Conn. Acad. Arts Sci. 3, 343 (1878).

${ }^{54}$ G. Wulff, Z. Kristallogr. 34, 449 (1901).

${ }^{55} \mathrm{~W}$. Kleber, Einführung in die Kristallographie (VEB Verlag Technik, Berlin, 1979).

${ }^{56}$ R. F. C. Farrow, G. R. Harp, R. F. Marks, T. A. Rabedeau, M. F. Toney, D. Weller, and S. S. P. Parkin, J. Cryst. Growth 133, 47 (1993). 